\title{
Correspondence:
}

\section{Health status of journalists}

Journalists, by virtue of their occupational requirements constitute a highly stressed group of professionals in the society. Sparse data are available regarding their health condition and the profile of the burden of diseases among journalists and their immediate family. The present prospective study of journalists and their family members was undertaken at Sri Venkateswara Institute of Medical Sciences (SVIMS), Tirupati during the period November 2010 and January 2011. In all of them, a detailed history was obtained including documentation of responses to Epworth Sleepiness Scale. ${ }^{1}$ A thorough physical examination, including anthropometry, screening for hypertension was carried out. Details of known co-morbid conditions were documented. Laboratory testing included haemogram; serum biochemistry including screening for diabetes mellitus, dyslipidaemia; liver function and renal function tests; urine examination; chest radiograph (postero-anterior view); and electrocardiogram. The study was funded by Sri Balaji Arogya Vara Prasadini (SBAVP) scheme of Tirumala Tirupati Devasthanams (TTD).

During the study period, 90 subjects (45 males) were studied. Their age range was 13-72 years. Obesity defined as body mass index (BMI) greater than $25 \mathrm{~kg} / \mathrm{m}^{2}$ was found in $46(51 \%)$ subjects. The prevalence of various diseases and dyslipidaemia that were identified are listed in Tables 1 and 2 respectively. ${ }^{2}$ Compared with prevalence figures of obesity among middle class subjects in India the figure of $51 \%$ observed in the present study is high and reflects the rising trends in obesity observed in Southeast Asia. ${ }^{3,4}$

Table 1: Prevalence of various diseases in journalists and their family members (n=90)

\begin{tabular}{ll}
\hline Disease & No. $(\boldsymbol{\%})$ \\
\hline Acid-peptic disease & $14(16)$ \\
Hypertension & $13(14)$ \\
Prehypertension $(\mathrm{SBP}>120<139 \mathrm{~mm} \mathrm{Hg} ;$ & \\
DBP $>80<89 \mathrm{~mm} \mathrm{Hg})$ & $42(46)$ \\
Diabetes mellitus & $10(11)$ \\
Anxiety disorder & $06(7)$ \\
Bronchial asthma & $06(7)$ \\
Excessive daytime sleepiness & $05(6)$ \\
\hline
\end{tabular}

$\mathrm{SBP}=$ systolic blood pressure DBP = diastolic blood pressure

Table 2: Prevalence of dyslipidaemia*

\begin{tabular}{ll}
\hline Risk factor & No. $(\%)$ \\
\hline High serum cholesterol $(>239 \mathrm{mg} / \mathrm{dL})$ & $19(21 \%)$ \\
High serum triglycerides $(>199 \mathrm{mg} / \mathrm{dL})$ & $14(16 \%)$ \\
$\begin{array}{l}\text { Low HDL }(<40 \mathrm{mg} / \mathrm{dL} \text { in males; }<50 \mathrm{mg} / \mathrm{dL} \\
\text { in females) }\end{array}$ & $43(48 \%)$ \\
\hline
\end{tabular}

*as defined in the National Cholesterol Education Program, Third Adult Treatment Panel (NCEP - ATP III) report (reference 2)

$\mathrm{HDL}=$ High density lipoprotein 
Obesity, hypertension, prehypertension, diabetes mellitus, dyslipidemia which are important coronary artery diseases (CAD) risk factors ${ }^{5}$ were found to be common problems among journalists and their family members. Reduced high density lipoprotein cholesterol was the most commonly observed lipid abnormality. Excessive daytime sleepiness, a harbinger of sleep disordered breathing was also frequently observed in the present study. High prevalence of acid-peptic disease and anxiety disorders reflect the high stress levels faced by these persons. Several of these health problems are modifiable with appropriate life-style modification and medications This information may be useful for health policy makers to evolve community level intervention measures.

\section{ACKNOWLEDGEMENT}

The author wishes to thank the residents and faculty members of the Department of Medicine, for their help in conducting this study.

\section{REFERENCES}

1. Johns MW. A new method for measuring daytime sleepiness: the Epworth Sleepiness Scale. Sleep 1991;14:540-5.

2. Expert Panel on Detection, Evaluation, and Treatment of High Blood Cholesterol in Adults. Executive Summary of The Third Report of The National Cholesterol Education Program (NCEP) Expert Panel on Detection, Evaluation, And Treatment of High Blood Cholesterol In Adults (Adult Treatment Panel III). JAMA 2001;285:2486-97.

3. Wang Y, Chen HJ, Shaikh S, Mathur P. Is obesity becoming a public health problem in India? Examine the shift from under- to overnutrition problems over time. Obes Rev 2009;10:456-74.

4. Narain JP, Garg R, Fric A. Non-communicable diseases in the South-East Asia region: burden, strategies and opportunities. Natl Med J India 2011;24:280-7.

5. Lee CM, Colagiuri S, Ezzati M, Woodward M. The burden of cardiovascular disease associated with high body mass index in the Asia-Pacific region. Obes Rev 2011;12:e454-9.

B.Vengamma

Director,

Sri Venkateswara Institute of Medical Sciences,

Tirupati

Received: 14 August, 2012.

Vengamma B. Health status of journalists. J Clin Sci Res 2012;1:209-10. 